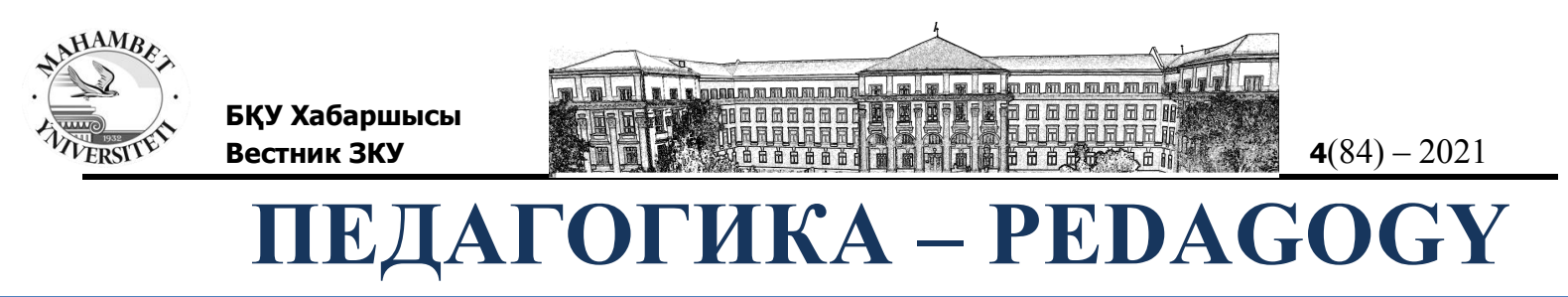

УДК 37.042

МРНТИ 14.29.41

DOI $10.37238 / 1680-0761.2021 .84(4) .26$
${ }^{1}$ Рыбакова Е.В. *, ${ }^{2}$ Султанова Р.М., ${ }^{3}$ Гаязова Г.А., ${ }^{4}$ Кутдусова А.А., ${ }^{5}$ Рыбаков Д.Г.

\author{
1,2,3,4 ФГБОУ ВО Башкирский государственный университет, \\ Уфа, Российская Федерация \\ ${ }^{5}$ Межрегиональная межведомственная Интернет-Гостиная «Белая Речь», \\ Белорецк, Российская Федерация \\ *Автор-корреспондент: evrybakova19@mail.ru
}

E-mail: evrybakova19@mail.ru

\title{
СОЦИАЛЬНО-ПРАВОВЫЕ КОМПОНЕНТЫ МОДЕЛИРОВАНИЯ АДРЕСНОГО СОПРОВОЖДЕНИЯ ОБУЧАЮЩИХСЯ С РАС
}

\begin{abstract}
Аннотация. Стремительное изменение нозологической картины современного детства приобретает ныне характер экспансии в отношении обучаюшихся $c$ расстройствами аутистического спектра (РАC). Научные, практико-ориентированные усилия граждан и институций, государственные, международные, сочиильные инициативы формируют продуктивный, эффективный ответ навстречу запросам сочиума и семей обучающихся, разрабатываются, апробируются, внедряются инновачионные технологические средства сопровождения и в соответствии с особыми образовательными потребностями детей и подростков - выявленными, прогнозируемыми, предполагаемыми. Учёные, преподаватели, специиалисты коррекичинного профиля, родители обучающихся, студенты БашГУ, представители общественности Республики Башкортостан, РФ, приняли заинтересованное участие в исследовательском проекте по моделированию адресных подходов поддержки обучающихся данной категории и их семей, отвечающих современным запросам и научным инновачиям в этой области.
\end{abstract}

Ключевые слова: обучаюшиеся с расстройствами аутистического спектра, нозологическая картина современного детства, особые образовательные потребности, сопровождение, обучающиеся.

\section{Введение}

Мировое сообщество претерпевает в настоящее время системный кризис по всем направлениям общественного развития. Беспокойство граждан и сообществ весьма оправданно, однако научный анализ текущих кризисных реалий закономерно может рассматриваться и с точки зрения ресурсного потенциала ситуации, динамических компонентов действительности, прогнозируемых факторов общественного развития. Собственно, и дефектологические компетенции ориентируют нас к выявлению компенсаторных, сверхкомпенсаторных возможностей сложных испытаний бытия.

Существенно, что современные реалии преобразования социума: средовые, идеологические, научные, информационно-технологические, урбанистические, профессиональные - системно коррелируют с проявлениями у детского населения средовых 


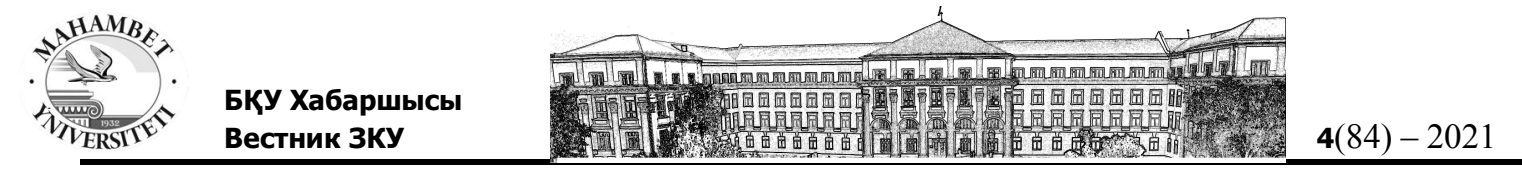

изменений коммуникативного статуса, социально-деятельностного развития, компонентов гражданственной готовности, проектной и личностно-преферентной природы. В целом нормативно развивающиеся (называемые ныне нормотипичными, нейронормальными) категории детей и подростков демонстрируют ныне своеобразие самопозиционирования, социализации, мотивации деятельности, структуры коммуникации и занятости. Обучающиеся с ограниченными возможностями здоровья (далее - ОВ3), с одной стороны, испытывают как закономерное, так и самобытное усугубление социально-деятельностной напряженности, а также повышенный риск перегрузки в социально-образовательной актуализации, с другой - цифровизация, дистанцированность, разноплановость, образные и клиповые компоненты средовой занятости, дискретность (то есть, например, фрагментация) и кратность (возможность повторения равных единиц информации, дублирования) дидактического пространства открывают определённые преимущества, связанные с повышением возможностейвариативного применения, тиражирования, выбора дистанции и формата использования дидактических средств, избирательного моделирования социальнообразовательного пространства, - то есть те ресурсные технологические направления, которые, согласно специфическим особенностям обучающихся с РАС, изучаемых учёными и практиками различных стран, наиболее перспективны как для совершенствования системы адресного сопровождения данной целевой категории детского населения (хотя, по результатам проведённого нашей авторской группой масштабного социальнопедагогического исследования, наблюдается стремительный запрос специалистов и родителей обучающихся на внедрение таких технологических подходов и в отношении других категорий обучающихся), - так для совершенствования собственно образовательных систем.

Научный поиск и разработки практиков в настоящее время привели к реализации ряда подходов к сопровождению обучающихся с РАС:

\section{ПОВЕДЕНЧЕСКИЕ ПОДХОДЫ}

ABA (Appliedbehavioranalysis) - Прикладной анализ поведения

VBA (Verbalbehavioranalysis) - Вербально-Поведенческий Анализ

Pivotal Response Treatment (PRT) - Обучение основным реакциям

TEACCH (Treatment and Education of Autistic and Related Communication Handicapped Children)

\section{РАЗВИВАЮЩИЕ ПОДХОДЫ}

Эмоционально-смысловой подход

DIR Floortime

Son-Rise

Dailylifetherapy - Ежедневная Жизненная Терапия

RDI - Программа развития межличностных отношений

\section{СЕНСОРНО-ПЕРЦЕПТИВНЫЕ ПОДХОДЫ}

Сенсорная интеграция

Томатис терапия

\section{ЭКЛЕКТИЧНЫЕ ПОДХОДЫ}

Модель SCERTS

TheMillerMethod - Метод Миллера

Общаясь с коллегами в ходе международных конференций, авторы убедились, что во многом наш научный проект резонирует с направлением DIR Floortime и вызывает живой интерес, готовность к диалогу представителей этого движения учёных, специалистов, родителей обучающихся, самих детей и подростков РАС, общественности, хотя преимущественная направленность наших исследований лежит в поле личностного, социального, правового, избирательного регулирования отношений с обучающимися с приматом именно запросов, инициативы, оценки и права вето самих обучающихся. 


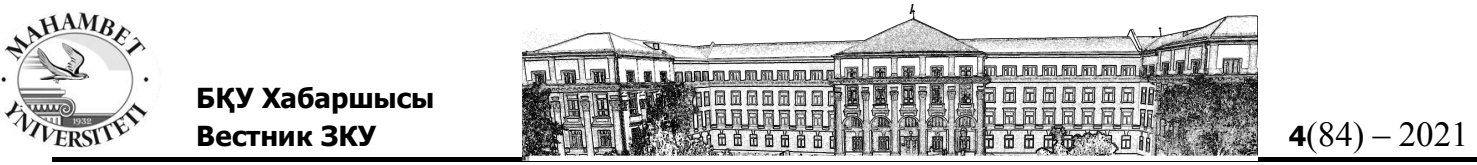

Проблемной представляется и неготовность педагогов обучать детей с такими сложными образовательными трудностями, объясняемая ожиданием адекватного результата, продуктивного ответа на проводимые социально-образовательные действия, что для обучающихся с РАС представляет область недостаточно продуктивную и само это ожидание, требования педагогов и родителей нередко вызывают у детей напряжённость, негативизм, протест различной степени выраженности.

Поскольку иные подходы в данном регистре недостаточно эффективны и зачастую оказываются контрпродуктивными, моделирование и внедрение подхода, помогающего преодолеть диссонансы и противостояния социально-образовательного процесса за счёт принципиальной гуманизации личностного, социально-правового поля организации адресного сопровождения обучающихся с РАС является актуальным.

Соответственно, гипотезой сотрудничества учёных, преподавателей, практиков, родителей, студентов, общественности в формате деятельности ППС кафедры педагогики факультета психологии БашГУ, аффилированных структур Межрегиональная Межведомственная Интернет-Гостиная «Белая Речь», Кабинет Консультирования иКоррекции, сайта ForumDidaktic, других ресурсов и сообществ, стало следующее утверждение: применение адресного социально-правового подхода к сопровождению обучающихся с РАС обеспечит существенное повышение эффективности коммуникации и образовательной занятости обучающихся, а также гармонизацию отношений всех участников социально-образовательного пространства.

\section{Материаль и методы исследования}

Участники исследования провели широкое изучение теоретических источников по данной проблеме, как в рамках названных направлений, так и иные статьи и пособия. Следует отметить, что при значительном росте, в связи с растущим научным, общественным и государственным ответственным интересом к данному проблемному кластеру, именно правой компонент образовательной занятости обучающихся с РАС, составной компонент их особых образовательных потребностей (впрочем, как и иных групп обучающихся, согласно, например, принципу демократизации образовательной среды, определённому ФГОС), не обрели пока системного научного освещения и практического изучения. Были проанализированы различные организационные подходы к сопровождению обучающихся, а также авторский опыт практиков региона и российских образовательных систем.

Проведены Круглые столы и проблемные дискуссии учёных и практиков с охватом широких тематических кластеров и локальных аспектов реализации целевых аспектов исследования.

Проведено тематическое заседание Ветеранского Педагогического Совета, позволившего сопоставить текущую ситуацию с распространением и системой сопровождения обучающихся с аутистическими проявлениями со сходными элементами в развитии детского населения ряда предшествующих периодов, а также педагогические подходы применительно к детям, имеющим трудности в коммуникации, образовательной занятости, речевой функции.

Организована работа Проект-мастерских под руководством и с методическим обеспечением авторской группы исследования.

Определены позиции продолжения исследовательской и практико-ориентированной работы в условиях КОВИД-мероприятий.

Разработаны модели дистанционного сопровождения обучающихся, актуализации цифровых средств обучения, коммуникации, досугового обеспечения и поддержки семей с осуществлением гибкого целенаправленного педагогического мониторинга и педагогической рефлексии.

Определены образовательные субъекты, специалисты которых приняли участие в проекте: образовательные организации и образовательные модули в организациях 
медицинского, социального профиля, частные организации сопровождения и общественные объединения. Разработаны методики целеполагания, адресного сопровождения, контроля и руководства, аспекты сотрудничества участников.

Для эффективной и гармоничной актуализации этих и других возможностей совершенствования социально-образовательного сотрудничества взрослых и детей в период активного, нередко драматичного преобразования общества необходим ряд условий, и в первую очередь - имеющих принципиально правовую отнесённость, поскольку системность проблематики востребует от всех участников созидательного сотрудничества высокой координированности, целесообразности, перспективной и этической ориентированности в ходе структурного роста и качественного развития системы адресной поддержки обучающихся и их семей, бюджетных и общественных организаций, сотрудничества исследователей и практиков, обеспечения безопасности образовательной среды и институционального соответствия.

И если законодательную, нормативно-правовую базу эффективно задают здесь ряд международных и отечественных инициатив и документов, Федеральных государственных образовательных стандартов, то гуманизация образовательных отношений заложена как в международных декларациях и ФГОС (например, позиция демократизации образовательной среды), так и в научной, методической литературе, проявляется она в практике передовых образовательных организаций, специалистов, семей и сообществ.

В нашей работе мы опираемся на классический базис межличностной культуры образования и общения, предпосылки которой есть и в античных источниках (диалоги Сократа и общение Аристотеля с учениками), на системное международное сотрудничество в данной области науки и практики, прогнозирование образовательной ситуации, изучение запросов семей обучающихся, акцентируя право личности обучающегося проявлять личные преференции, вкусы, актуализировать проектные запросы, креативные возможности, индивидуализировать образовательную занятость и режим сотрудничества со взрослыми.

Мы рассматриваем здесь преимущественно категорию обучающихся с PAC, тем более что производные, сопутствующие состояния у детей и других нозологических групп также обнаруживают сходные проявления той или иной этиологии. Эти дети изучались авторами и нашими коллегами в формате непрерывного образования специалистов коррекционного профиля, педагогической практики студентов, консультирования и супервизии руководителей образовательных организаций, специалистов и родителей детей с PAC по запросу, собственной диагностико-коррекционной практики авторов.

Стремительно растущая и раскрывающая всё более разнородные аспекты развития и проблематику адресного сопровождения категория обучающихся с расстройствами аутистического спектра знаменует собой картину развития социума в целом. Сообщения выросших и благоприятно адаптировавшихся к социуму граждан с расстройствами аутистического спектра показывают как скрытую потребность их в общении, в той или иной степени осознанную, так и готовность к восприятию, актуализации индивидуально приемлемых контентов [1], проектной самоактуализации.

Нередко гуманистическая позиция учёных [2, с. 71-78], специалистов, родителей, первоначально противостоящая устоявшимся взглядам, подтверждается практикой и мнением включившихся в социальную коммуникацию граждан с РАС. Так, например, меняются взгляды на вербальную персеверацию, применение нерасчлененных текстов, выбор иноязычной лексики для коммуникации, кажущиеся капризы в дидактическом выборе [3, с. 149-154] и даже проявления аутоагрессии - первоначально воспринимаемые как однозначно патологические симптомы и явления, данные реалии могут представлять приспособительные механизмы и продуктивные приёмы [4, с.62-65; 5, с. 761-771]. Как минимум, современные специалисты не исключают такие проявления из праксиса 
обучающихся, растёт также опыт эффективной актуализации различных нетипичных реакций и способов действия.

Текущий период развития адресного сопровождения обучающихся с особыми образовательными потребностями (ОВ3) характеризуется, с одной стороны, совмещением нормативно-правовых основ системной поддержки детей различных нозологических групп (международные правовые основы, Федеральные государственные образовательные стандарты и др.) с позициями интерсубьектной, личностной ориентированности (античные, современные, перспективно значимые тренды, методические достижения и механизмы гуманизации образования) [6; 7, с. 342], с другой - интеграцией подходов, разрабатываемых для одних категорий обучающихся с ОВ3, для других целевых групп специального образования, а также для одаренных детей и нормотипичных обучающихся.

Для обеспечения этих продуктивных проявлений и в качестве осуществления социально-образовательных потребностей объединяются социально ответственные и научно достоверные усилия на каждом этапе развития общего и специального образования.

Данный период принципиального и субъектного совершенствования социальнообразовательного сотрудничества всех участников современного образования требует, на наш взгляд, определить, осуществлять и развивать ряд следующих принципов:

- ребёнок не обязан отвечать на наши обращения и отвечать нашим педагогически, родственным, общественным ожиданиям - это мы должны найти приемлемые для них и безопасные подходы, доступно и привлекательно информируя о них обучающихся, учитывая их возрастающие критические и проектные возможности, инициативы;

- наши представления об обучающемся в той или иной степени дефицитарны, неточны, ошибочны, оценка возможностей ребёнка характеризует лишь наш взгляд, нашу интерпретацию доступной нам информации, мы должны поддерживать и совершенствовать нашу готовность принять, благоприятно и достаточно безопасно актуализировать какие-либо проявления активности ребёнка в качестве деятельностного, личностного, интегративного, коммуникативного ресурса, варьируя подходы и демонстрируя личную деятельную толерантность;

- ребёнок имеет право на собственный выбор, в том числе отрицательный (и это тоже его образовательная потребность, личностная и компетентностная), мнение, оценку, инициативу, темп и дистанцию деятельности;

- обучающийся имеет право на неадекватное, особенно на наш ситуативный взгляд, поведение, напротив, это наша креативная состоятельность и ответственность обеспечивает и эффективность, и безопасность сотрудничества;

- нам следует принять, что ребёнок сотрудничает с нами и тогда, когда это нам неявно, - и обеспечивать ему пространство для самоактуализации, а также для расширения столь неоднозначного праксиса;

- примат активности обучающегося предполагает как соблюдение педагогической паузы, так и дискретности социально-образовательного диалога, чтобы неожиданные, тем более - спонтанные реакции, проявления обучающегося получали благоприятный для развития диалога и самого ребёнка ответ;

- отсутствие явного запроса на информацию как дидактического, так и иного плана не означает отсутствие потребности обучающегося в ознакомлении и вариативном доступе к образовательным средствам, курсам различного уровня сложности (актуального, ближайшей зоны развития, паспортного возраста, превышающего уровня сложности, пониженного, вкусовой и досуговой отнесенности, информации о его состоянии, возможностях, перспективах, опыте, проблемах, достижениях других обучающихся и сообществах, социальных, технических, иных аспектах общественной жизни; 
- сопровождающие субъекты несут ответственность за доступную актуализацию личностны, самобытных, интегрирующих, креативных, проектных, событийнодеятельностных, сверхкомпенсаторных ресурсов обучения.

Существенно, что общественный запрос в отношении такого системного социализирующего подхода растёт в семьях и образовательных организациях, сопровождающих детей и иных нозологических состояний, равно как и детей относительно нормативного развития, одарённых, высокомотивированных.

\section{Результаты исследования}

Обсуждая проблемы и достигнутые результаты в ходе проведённого исследования, участники пришли к следующим выводам:

- Применение разработанных подходов и принципов сопровождения значительно снижает напряжённость взрослых и детей (субъективно - заметно уже в течение первой недели регулярного сопровождения, первого месяца при периодическом посещении), проявления агрессивных реакций и аффективных вспышек в ходе занятий падает в среднем на 15-20\% (в дальнейшем наблюдаются рецидивы негативизма, но слабо выраженные, постепенно угасающие, требующие всё меньше времени и активности взрослых для купирования социальнонеблагоприятных форм актуализации), слабеют и становятся менее регулярными негативные проявления в отношении привычных других раздражителей (показатели расходятся значительно, однако наличие тенденции подтверждается большинством респондентов - 75\%), минимизируются показатели защитной готовности на занятиях (25-45\%) и вне занятий со специалистами (до $35 \%$ при постоянном сопровождении, до $15 \%$ - при периодическом).

- Расширяется преферентная сфера занятости обучающихся (от 30 до 55\%, по разным данным).

- Проявляются элементы целенаправленного регулирования общения и образовательного сотрудничества.

- Проявления интереса к личности обучающего и сотрудничеству с ним (от 20 до $45 \%)$.

- Растёт субъективная удовлетворённость сопровождающих педагогов (до 85\%) и родителей (до 60\%).

Фрагментарно предлагаемые принципы авторы реализовали в отношении других категорий детского населения, получив также благоприятные результаты и отзывы. В перспективе предполагаем продолжить эту работу в более широком регистре.

\section{Заключение}

Проведённое исследование доказало действенность и продуктивность разработанного подхода и значимость критериального, ценностного, прогностического компонентов научного моделирования, контроля, анализа.

Организационные и методические аспекты подтвердили свою эффективность, продуктивность, доступность для практико-ориентированного применения и обсуждения с различными категориями населения.

Участники мероприятий выразили удовлетворённость содержанием, организацией и продуктивностью сотрудничества, а также готовность в дальнейшем следовать принципам и подходам, подтвердившим свою действенность, актуальность и резонансность как в образовательных системах, так и в частном формате сопровождения.

\section{Благодарности}

Авторы и другие участники исследования выражают глубокую благодарность научному и духовному лидеру проведённой работы, заведующему кафедрой педагогики БашГУ д.п.н. Гаязову Альфису Суфияновичу, чей академический базис и международный авторитет придал нашему сотрудничеству масштабность и резонансность. 
Авторская группа благодарит участников проектных групп исследования, интерес, ответственное отношение к сотрудничеству и творческая активность которых поддержали нас в нашем научном поиске.

\section{ЛИТЕРАТУРА}

[1] Гаязов А.С. Индивидуальные траектории образования личности [Электронный pecypc] / А.С. Гаязов // Режим доступа: http://www.raop.ru/index.php?id=878;

[2] Гаязов А. С. Новые реалии современного мира и перспективы образовательной деятельности / А. С. Гаязов // Вестник Курганского государственного университета. - 2019. № 3 (54). - С. 71-78.;

[3] Рыбакова Е.В., Султанова Р.М., Гаязова Г.А. Организация блока вариативных стимульных материалов и пособий для обеспечения избирательной познавательной активности детей с РАС. - В сборнике: Деятельность ПМПК в современных условиях. Ключевые ориентиры. Сборник материалов Всероссийской конференции. Российский университет дружбы народов. 2018. С. 149-154;

[4] Султанова Р.М., Гаязова Г.А., Рыбакова Е.В. Интерсубъектный компонент в системе сопровождения ребёнка с РАС. - В сборнике: Теоретические и прикладные проблемы психологического здоровья и экологии человека. Сборник научных статей Международной научно-практической конференции.отв. редактор Р.Р. Халфина. 2017. С. 62-65;

[5] Рыбакова Е. В., Султанова Р. М., Гаязова Г. А. Индивидуализированный педагогический мониторинг как обеспечение условий эффективного неврологического сопровождения детей с ограниченными возможностями здоровья. - Дефектология в свете современных нейронаук: теоретические и практические аспекты: Сб. материалов I Международной научной конференции, 23-24 апреля 2021 г. / Под общ.ред. Т. Г. Визель. М.: Когито-Центр - Московский институт психоанализа, 2021. - 825 с., стр. 761-771.

[6] Рыбакова Е.В., Султанова Р.М., Гаязова Г.А., Рыбаков Д.Г. Развитие инклюзивного образования на текущем этапе. Региональный опыт. Научные исследования и инновации. Сборник статей VI Международной научно-практической конференции: сборник статей, [электронное издание сетевого распространения] / Под ред. Н.В. Емельянова. - М.: “КДУ”, “Добросвет", 2021. - 136 с. - URL: https://bookonlime.ru/node/39417 - DOI: 10.31453/kdu.ru.978-5-7913-1173-3-2021-136.ISBN 978-5-7913-1173

[7] Рыбакова Е. В. Изучение и поддержка готовности обучающихся к проектным, креативным, индивидуально приоритетным формам сотрудничества с преподавателями с применением разработанных Л. С. Выготским принципов и подходов. Актуальные проблемы культурно-исторической психологии: материалы Первого международного симпозиума по культурно-исторической психологии (Новосибирск, 17-19 ноября 2020 г.) / сост. Т. Э. Сизикова, Н. Н. Попова, О. А. Дураченко. - Новосибирск : Изд-во НГПУ, 2020. - 508 с. Текст: непосредственный. ISBN 978-5-00104-601-1, стр. 342-328.

\section{REFERENCES}

[1] Gayazov, A.S. Individual'nye traektorii obrazovaniya lichnosti [Individual trajectories of personality education] Retrieved from: http://www.raop.ru/index.php?id=878 [in Russian].

[2] Gayazov, A. S. (2019) Novye realii sovremennogo mira i perspektivy obrazovatel'noj deyatel'nosti [New realities of the modern world and prospects of educational activity] Vestnik Kurganskogo gosudarstvennogo universiteta - Bulletin of the Kurgan State University, 3 (54) , 7178 [in Russian].

[3] Rybakova, E.V., Sultanova, R.M. \& Gayazova, G.A. (2018) Organizaciya bloka variativnyh stimul'nyh materialov $\mathrm{i}$ posobij dlya obespecheniya izbiratel'noj poznavatel'noj aktivnosti detej s RAS [Organization of a block of variable stimulus materials and manuals to 
ensure selective cognitive activity of children with ASD]. Preceedings from Deyatel'nost' PMPK v sovremennyh usloviyah. Klyuchevye orientiry. Vserossijskaia konferencaia - All-Russian conference. (pp. 149-154) Rossijskij universitet druzhby narodov [in Russian].

[4] Sultanova, R.M., Gayazova, G.A. \& Rybakova, E.V. (2017) Intersub"ektnyj komponent $\mathrm{v}$ sisteme soprovozhdeniya rebyonka $\mathrm{s}$ RAS [Intersubjective component in the system of accompanying a child with ASD]. Preceedings from Teoreticheskie i prikladnye problemy psihologicheskogo zdorov'ya i ekologii cheloveka. Mezhdunarodnaia nauchno-prakticheskaia International Scientific and Practical Conference, 62-65. R.R. Halfina (Ed.) [in Russian].

[5] Rybakova, E. V., Sultanova, R. M. \& Gayazova, G. A. (2021). Individualizirovannyj pedagogicheskij monitoring kak obespechenie uslovij effektivnogo nevrologicheskogo soprovozhdeniya detej s ogranichennymi vozmozhnostyami zdorov'ya [Individualized pedagogical monitoring as providing conditions for effective neurological support of children with disabilities]. T. G. Vizel' (Ed.). Preceedings from Defektologiya v svete sovremennyh nejronauk: teoreticheskie i prakticheskie aspekty. I Mezhdunarodnaia nauchno-prakticheskaia (23-24 aprelya 2021 g.) - I International Scientific Conference, M.: Kogito-Centr, Moskovskij institute psihoanaliza. (pp. 761771). [in Russian].

[6] Rybakova, E.V., Sultanova, R.M., Gayazova, G.A. \& Rybakov, D.G. (2021) Razvitie inklyuzivnogo obrazovaniya na tekushchem etape. Regional'nyj opyt. [Development of inclusive education at the current stage. Regional experience.]. N.V. Emel'yanova (Ed.). Preceedings from Nauchnye issledovaniya iinnovacii - Research and innovation. VI Mezhdunarodnaia nauchnoprakticheskaia - VI International Scientific and Practical Conference (136 p.) M.: "KDU", "Dobrosvet". Retrieved from https://bookonlime.ru/node/39417 - DOI: 10.31453/kdu.ru.978-57913-1173-3-2021-136. ISBN 978-5-7913-1173 [in Russian].

[7] Rybakova, E. V., Sizikova, T. E., Popova, N. N. \& Durachenko, O. A. (2020) Izuchenie i podderzhka gotovnosti obuchayushchihsya k proektnym, kreativnym, individual'no prioritetnym formam sotrudnichestva $\mathrm{s}$ prepodavatelyami $\mathrm{s}$ primeneniem razrabotannyh L. S. Vygotskim principov i podhodov. [Study and support of students' readiness for project, creative, individually priority forms of cooperation with teachers using principles and approaches developed by L. S. Vygotsky]. Preceedings from Aktual'nye problemy kul'turno-istoricheskoj psihologii. Pervyj mezhdunarodnyj simpozium po kul'turno-istoricheskoj psihologii (Novosibirsk, 17-19 noyabrya 2020 g.) - The first international symposium on cultural and historical psychology. Novosibirsk: Izd-vo NGPU. (508 p.) ISBN 978-5-00104-601-1, pp. 342-328. [in Russian].

\section{Рыбакова Е.В., Султанова Р.М., Гаязова Г.А., Кутдусова А.А., Рыбаков Д.Г. АСБ БАР БІЛІМ АЛУШЫЛАРДЫ АТАУЛЫ СУЙЕМЕЛДЕУДІ МОДЕЛЬДЕУДІН ӘЛЕУМЕТТІК-КҰҚЫҚТЫҚ КОМПОНЕНТТЕРІ}

Андатпа. Қазіргі заманғы балалық шақтың нозологиялық көрінісінің қарқынды өзгеруі аутистік спектрдің бұзылулары (АСБ) бар білім алушыларға қатысты негізгі сипатқа ие болып отыр. Азаматтар мен институттардың ғылыми, практикаға бағытталған күш-жігері, Мемлекеттік, Халықаралық, әлеуметтік бастамалар социум мен білім алушылар отбасыларының сұраныстарына өнімді, тиімді жауап қалыптастырады, инновациялық технологиялық сүйемелдеу құралдарын әзірлейді, сынақтан өткізеді, балалар мен жасөспірімдердің ерекше білім беру қажеттіліктеріне сәйкес - анықталған, болжанатын сүйемелдеуді енгізеді. Ғалымдар, оқытушылар, түзету профилінің мамандары, студенттердің ата-аналары, БашМУ студенттері, Башқұртстан Республикасы, Ресей Федерациясының қоғам өкілдері осы санаттағы студенттер мен олардың отбасыларын қолдаудың қазіргі заманғы сұраныстар мен осы саладағы ғылыми инновацияларға жауап беретін мақсатты тәсілдерін модельдеу бойынша зерттеу жобасына қызығушылық танытты. 
Кілт сөздер: аутистік спектрдің бұзылулары бар білім алушылар, қазіргі заманғы балалық шақтың нозологиялық көрінісі, ерекше білім беру қажеттіліктері, алып жүру, білім алушылар.

\section{Rybakova Elena, Sultanova Roza, Gayazova Gulshat, Kutdusova Anastasiya, Rybakov Dmitry SOCIO-LEGAL COMPONENTS OF MODELING TARGETED SUPPORT OF STUDENTS WITH ASD}

Annotation. The rapid change in the nosological picture of modern childhood is now acquiring the character of expansion in relation to students with autism spectrum disorders (ASD).

Scientific, practice-oriented efforts of citizens and institutions, state, international, social initiatives form a productive, effective response to the needs of society and families of students, innovative technological means of support are developed, tested, introduced and in accordance with the special educational needs of children and adolescents - identified, predictable, predictable. Scientists, teachers, specialists in the correctional profile, parents of students, students of BashSU, representatives of the public of the Republic of Bashkortostan, RF, took an interested part in a research project on modeling targeted approaches to support students of this category and their families that meet modern needs and scientific innovations in this area.

Keywords: students with autism spectrum disorders, nosological picture of modern childhood, special educational needs, support, students. 